\title{
Management Challenges of Post-Authoritarian Developmentalist Industrial Geography in East Asia
}

\author{
John Walsh \\ School of Management, Shinawatra University, Bangkok, Thailand \\ jcwalsh@siu.ac.th
}

\begin{abstract}
The origin of contemporary East Asian economic development coincided with and was to some extent caused by the consequences of the Cold War. It was characterized by state-led developmental models focusing on import-substituting, export-oriented manufacturing with low labour cost competitiveness. States generally designated specific areas in which these activities could take place and regulated all aspects of their conduct and the distribution of profits resulting from them. As at least some of the states involved have moved towards a post-authoritarian stage of development, the places in which industrial development has taken place have broadened in scope and followed private rather than public sector priorities. This paper examines this trend and then identifies the principal management challenges arising from it.
\end{abstract}

Keywords: East Asia, industrialization, infrastructure, authoritarianism, industrial geography

\section{Introduction}

The rise of East Asia to economic ascendancy has taken place since the conclusion of WWII. Fearing that Japan might lean towards a Communist revolution, the US authorities opened their markets to Japanese exports manufactured in Japanese factories unencumbered with worker's rights, health and safety issues or intellectual property protection. A huge boost to the region was provided by the outbreak of the Korean Civil War, which offered opportunities for contracts with local manufacturers in a variety of fields, the chance to send troops to the combat zone in return for concessions and the development of recreation facilities for US and allied troops in several convenient port locations. Subsequently, the Korean economy received a similar boost through its role in the Second Indochina War (or Vietnam War). Manufacturing was based on original equipment manufacturer (OEM) products - that is, items with any embedded intellectual property belonging to non-national interests and with competitiveness provided by low labour costs. In Japan, followed by Korea, Taiwan, Thailand and now China and Vietnam, these low labour costs have been managed by moving workers into the manufacturing sector from the large and underemployed agricultural sector and by suppressing rights of association, collective bargaining and freedom of speech. The roots of many an East Asian economic so-called miracle have been refreshed with the blood of inconvenient trade unionists. In due course, the success of economic development led to generally rising standards of living that eroded low labour cost competitiveness, although some have sought to wring the maximum possible value from this asset with force. Eventually the governments of Japan, Korea and Taiwan, in particular, have realized that the model no longer has meaningful application in their countries and have orchestrated a qualitative change in economic and social structure: to add value to production through creativity is benefited by (a sometimes limited form of) democracy, better advanced education institutions and social solidarity. Autocrats have been replaced, therefore, and occasionally jailed for such crimes as corruption, abuse of power and so forth. Seizure of assets from those involved demonstrates that the state will no longer tolerate the methods of the past. It is essential to understand why these changes are occurring and what implications they will have for the ways of life and patterns of work for citizens across East Asia. Authoritarianism appeared to be invincibly linked to East Asian states but is being levered out, unexpectedly, even from such outposts as Burma [Myanmar]. The period of authoritarianism had led to a specific form of uneven development that was intended to maximize the benefits received by those in hierarchies of power controlling the distribution of resources. Post-authoritarian will, therefore, give rise to different but possibly, equally distinctive forms of uneven development, no doubt heavily influenced by the differential spread of advanced capitalism across the geographical territory explored. In this paper, East Asia is defined as the capitalist countries of northeast Asia (i.e. South Korea, Japan and China) and the ten countries of the Association of Southeast Asian Nations (ASEAN) (i.e. Thailand, Burma, Cambodia, Laos, Vietnam, Malaysia, Indonesia, Brunei, Singapore and the Philippines). The temporal focus is from the conclusion of WWII in 1945 until the present time, with some recommendations drawn, which relate to future developments. This paper employs the 
analytical case study method: that is, data has been gathered from a variety of sources and over an extended period of time and interrogated using content analysis approaches with a view to providing a coherent and systematic understanding of the issues researched. Such an approach can generate accurate and useful explanations of events and situations within an analytical framework, which can be used to develop understanding in a thorough, rigorous and systematic manner (Flyvbjerg, 2006).

\section{Authoritarian Development}

As the Cold War settled on East Asia, the western world, now led by the USA, permitted both the return of the colonial age and the imposition of authoritarian, often military regimes on the countries involved under the pretext of fighting Communism. From Korea to Thailand to Indonesia, state violence was used against peasants, workers and political opponents in the effort to construct unified, monolithic and dedicated anti-Communist regimes. To develop these economies, access was permitted to American domestic markets to Asian exporters and the proceeds used in part to create strengthened elite able and willing to resist any meaningful form of political change. It has been argued that the period during which rapid industrialization took place coincided with a potent and positive cycle of economic growth, which cannot be, replicated (Wallerstein, 2010). This argument sees future economic growth based on translocation of production to Asian countries as being fatally undermined by the structural crisis of reduced profits in the absence of breakthrough new technologies (Balakrishnan, 2009). It is certainly true that continued economic growth within the existing development paradigm will continue to place extreme pressure on the physical environment and contribute to global climate change (Olson, 2009). Aspects of culture within individual states which were considered useful in this form of authoritarian developmentalism were promoted as virtuous representations of nationalism and unity, while other less valuable aspects were downplayed or demonized (Berger, 2003; Kim, 2010). This is most evident in the re-creation of Confucianism as neo-Confucianism and its intimate relationship with the so-called 'Asian values' propounded by influential leaders such as Lee Kuan Yew and Dr Mahathir Mohamed, not to mention leaders of the Chinese Communist Party (Emmerson, 1995; Gong, 1989). It is often concluded that the success first of East Asian industrialization as a whole and second of the emergence of specific East Asian multinational enterprises (MNEs) as prominent organizations has relied upon a combination of state influences and cultural factors (e.g. Chang, 2011; Amsden, 1992; Ward, Pearson and Entrekin, 1992). Authoritarian development is characterized by state-led economic development based on a version of the East Asian Economic Model (EAEM): that is, import-substituting, export-oriented low cost manufacturing with competitive advantage based on labour cost suppression. Lewisian movements of labour explain structural change within the labour market (Cai and Wang, 2010) and costs have been further suppressed by regular uses of force by the state to repress freedom of speech, freedom of association and collective bargaining, not to mention the outlawing of political parties that might meaningfully represent labour interests at the national or provincial level. International capitalism in the modern age has required this of governments in their treatment of labour (Walker, 1999). The authoritarian nature of this developmentalism has implications for the spatial arrangement of economic activities, which are explored in the next section.

\section{Industrial Geography and Spatial Arrangement of Economic Activities}

Industrial geography is a field of study that concerns the disposition of industrial facilities and related infrastructure in connection with the physical environment of a particular state. A geographical area in which industrial activities are deliberately located by the state or by private sector actors may be considered an industrial estate (IE). All forms of IE may be incorporated in the concept of the Special Economic Zone (SEZ), which is a specified geographic area in which the normal laws of the land are in some way varied for specific developmental and economic purposes. Perhaps the most well-known examples of SEZ usage is in China when, under the Open Door policy of 1979, a series of SEZs were established on the eastern coast and have become the leaders of China's export-oriented industrial growth strategy (Ge, 1999). An IE (or park) is a subset of SEZs and consists of a geographical area in which infrastructure and facilities are provided with a view to encouraging investment there. Investors aim to achieve lower costs by locating in the IE and may obtain synergies through proximity to other firms, which might have complementary resources or competencies. Some IEs are designated as Free Trade Zones (FTZs) in which goods may be produced without any taxation or duties imposed upon them. Generally, FTZs are aimed at production for export overseas since; otherwise, it would represent a significant increase in competitiveness and possibly unfair competition in the domestic market. An FTZ, then, is usually also an Export Processing Zone (EPZ), which is an IE in which privileges are offered to 
production of goods for export. Some EPZs will be FTZs but not all, since benefits might include reduced taxation but not zero taxation. From an economics perspective, the benefits of a geographical clustering of firms dates to the work of Marshall (1890), who argued that traded interdependencies (e.g. in supplier and labour markets) and untraded opportunities (e.g. social interaction and information exchange) act to promote competitiveness. In addition, some IEs are designated as technology parks or science parks and, in this case, are placed in proximity to universities or other advanced learning institutions. These parks are expected to help produce advanced products through the synergies possible from inter-connections among firms. In the case where a university is involved, a science park might offer opportunities for university faculty to establish their own businesses and might be connected with a business incubator.

IEs are generally located in sites, which have good transportation links both to sources of important inputs and to means of exporting. Depending on the type of production, it may be preferable for the location to be close to an airport or a seaport. Map Ta Phut IE, for example, largely deals with bulky industrial products and so is located on the coast where inputs and outputs can be transported most conveniently. In some cases, the IE is located close to a specific resource, which is to be extracted or processed. Irrespective of the location, it is expected as a minimum that the IE provides reliable supplies of electricity and water. For more advanced IEs, reliable high-speed internet connections will also be expected. Many IEs will have their own generating stations in order to guarantee these supplies and will maintain private security services. This is particularly important for IEs in countries, which have low levels of effective policing and where industrial goods represent valuable items that might be stolen. IEs may belong to the private or public sector or a partnership of private and public. Public sector IEs are more likely to be aimed at bringing about national developmental goals while private sector IEs are more likely to be aimed at making profits. Of course, there may be a considerable degree of overlap between the two types. For countries with few resources or technical expertise, it may be advantageous for the host government to hire private sector firms from overseas to construct and possibly operate the IE for some period on a turnkey or BOT (build-operate-transfer) basis. The Suzhou Industrial Estate in Southern China, for example, was built with considerable input from Singapore, where spare capital had accumulated and there was a need for additional space and labour, which, according to the theory, could be provided by China (e.g. Pereira, 2004). IEs, which attract many factories in labour-intensive sectors, which have been common in Thailand, also need to consider accommodation for those workers. Since IEs tend not to be close to urban areas with widely available spare accommodation, then dormitories must be created for workers and, in some cases, additional family members. Firms will also need to consider providing transportation and catering services. Such IEs tend to act as magnets for labour migration, since the desirability of jobs varies from province to province, depending on the relative wealth of each one. In Thailand, for example, the IE at Lampang has largely drawn workers from the northeastern Isan region where incomes are lowest. New jobs can be created by IEs, in other words, that are then taken by out-of-town people (Walsh and Anantarangsi, 2009).

The developmental goals that the state can attempt to promote with IEs include both national and regional levels. At the regional level, a government can create an IE as a means of increasing employment and investment in a depressed area. Japanese manufacturing projects were, for example, encouraged in parts of the UK badly affected by the closure of the mining industry (e.g. Morris, 1988). Such efforts need not just be reactive responses to depressed conditions but can b e positive efforts to develop competitive advantages in an area through promoting positive linkages between organizations and between different areas. The opening of bridges and roads better linking Thailand and Laos through the Second and Third cross-Mekong bridges in particular has provided firms in cities such as Khon Kaen with much greater market opportunities in other Mekong region states, particularly in goods which are comparatively low value but bulky and, hence, suitable for road transportation. One effect of the relocation of the Burmese capital from Yangon to Naypyidaw has, among other effects, improved the transportation links between important economic regions in the country and cross-country border points (Preecharushh, 20090. This infrastructure has been built to a considerable extent by Chinese capital, at least partly with a view to improving economic co-operation between Burma and China, not least with respect to piping oil and gas from offshore Burmese fields to Chinese territory. This improvement in infrastructure is exemplified by the development of a new IE project in Dawei (or Tavoy) (Linn, 2010) on the southern coast of the Kra isthmus and the site of a historically important port. It remains to be seen what kind of economic activities will in fact take place there, to what degree genuine competitive advantages are possible and what working conditions are in force for workers in factories in the estate. IE development has not reached a final point, since states and non-state institutions continue to try to find new ways of refining and improving SEZ projects through improved linkages, training, fostering of new clusters of firms and so 
forth. The theoretical basis of such developments has been provided by the original work by Porter (1998) and the many attempts to expand upon it. The concept is that successful industrial sectors will emerge in some specific geographical locations if, for various reasons, the important demand and supply conditions are present in or near that area. Hollywood is the obvious example for the film industry. Not only is talent drawn to California because of the presence of studios but also there is access to venture capital and good physical conditions to make films. In some cases, therefore, it should be possible to identify the specific conditions that are required to make a successful industrial cluster and then to create one or else encourage other actors to help to provide it. The state of knowledge of their prospects for economic success concerning IEs from around the world has become such that authorities as august as the World Bank has begun to issue guidelines and lessons from practice (e.g. Zeng, 2010; Farole, 2011).

The ability actually to bring this to pass has yet proved largely elusive, which has given rise to new thinking about how to intensify the value created in specific geographical areas. In Southern China, for example, this attempt is being led by the Guangdong provincial government, which has been moving to create 'specialised towns' which focus on creating a high spatial concentration of firms producing one or a very small number of items (Barbieri, Di Tommaso and Bonnini, 2010), owing to the increased specialization that such actions are known to have produced. In Thailand, a research team led by Porter was commissioned by the government to identify a series of potential clusters that would help to take the economy beyond the factory age of low wage competitiveness in low value added manufactured commodities. This identified areas such as the bio-agricultural sector, fashion and parts of what has become known as the knowledge economy. However, the 2006 military coup and subsequent political developments, efforts to create these clusters have largely been abandoned. Instead, the EAEM - low wages, export-oriented, low value-added manufacturing - has been reinstated as the principal means of development. Understanding IEs and their role has, therefore, returned to being a central concern in the effort to make the Thai economy more competitive in an international environment in which China and Vietnam already pose a significant threat to challenge for inward investment, while neighbouring Cambodia has recently entered into its own version of the factory age, with its government agencies enthusiastically pointing to the cheapness of its labour as the means of securing its own improved economic opportunities (Kunmakara, 2010) and shown themselves willing to take whatever actions are required to move inconvenient people out of the way of its developmental infrastructure projects (Crispin, 2007). Authoritarian industrial geography differs from economic or rational industrial geography in that normal criteria for selecting activities and locations may be set aside in favour of political motivations. The decisions that are made require negotiation with private sector partners, in one form or another. The relationship between private and public sectors in this regard has varied from genuine partnership to force majeure, although the most common arrangement is that private sector individuals have been provided with incentives to do as the public sector bids and individuals attached to the elites in power may take leadership roles in private sector initiatives to ensure compliance. This is explained further in the next section.

\section{The Role of Corporations}

In the western world, states are broadly divided between those who place the onus for development and welfare on the shoulders of the individual, anticipating that small government will enable corporations and hence jobs to flourish (Anglo-Saxon model) and those which work in conjunction with the private sector to ensure that developmental goals are met by a partnership (European or Scandinavian model). In the latter, corporations work with government to provide more or less guaranteed employment; while the state ensures that, the employees involved receive the training they need at the state's expense. When it came to East Asia, while states would have preferred to have followed the European model, they lacked the resources to do so. Unable to trust corporations to do the right thing for the country of their own volition and unable to provide training and development itself, the state made a bargain with the private sector: meet developmental goals and the state will turn a blind eye to the methods, while instigating a legislative framework and institutional arrangements that would permit corporations to do whatever was necessary. In Japan and Korea, therefore, Confucian paternalism created long-term employment contracts without which workers could fall rapidly into indigence. Corporations were alternately cajoled and bullied into abiding by the social contract into which they had entered with the state. Naturally, those corporations took advantage of the latitude offered to them by engineering situations in which, in the future, they could ensure that they were free from state controls. Overseas investment in everything from industrial estates to bonds to luxury consumer goods placed funds beyond the reach of home state governments. In Thailand, for example, the extremely large and diversified Charoen Pokphand 
Corporation has effectively removed itself from state supervision by moving its locus of control to its investments in a Chinese economy now fully embarked on its own East Asian Economic Model. The same was achieved to a lesser extent in Singapore and Taiwan, where the state preferred to act through government-linked firms, which offered extensive ties and connections between partners that were difficult to unravel unilaterally. Now, in the Mekong region in particular, one of the principal dynamic features affecting economic growth is the use of overseas Chinese organizations to help bring about developmental goals of the Chinese state: e.g., securing long-term, stable access to required resources and developing the physical infrastructure that will facilitate the distribution of Chinese goods and services. It will be of considerable interest and importance to observe the extent to which these overseas corporations will in due course be able to exercise any form of autonomy in their own right or whether the central government will continue to exercise its will from afar.

From Authoritarianism to Post-Authoritarianism: The early stages of post-WWII authoritarianism in East Asia were accompanied by systematic efforts both to exclude certain classes of people (e.g. peasants and workers) from political representation and to establish a pathway to a bourgeois political settlement that prevented any meaningful questioning of the capitalist system (e.g. Berger, 2003). This was conducted both by local ruling elites, mainly in the military and their allies, in some cases supported by US-backed activities. With economies locked in to manufacturing paradigms reliant on access to western markets and regulated by the institutions of the Washington Consensus, East Asian people were conditioned to internalize the belief that only by continuing in the same vein could not just economic progress be made but, also, stability and unity in the country as a whole. However, certain changes occurred which meant that a static pattern could not remain in force indefinitely. Not the least of these changes was the entry of new states at the bottom rung of the East Asian Economic Model, notably Vietnam and China, whose willingness and ability to provide even lower labour costs has provided potent competition for existing manufacturer-exporters. Second, such an economy reaches a position, which the World Bank has labeled the 'Middle Income Trap,' under which it, becomes clear that the means by which a low income country can become a middle income country are not the same means by which a middle income country can become a high income country. This second phase of progress seems to require a greater degree of reliance on the private sector, supported by the state's enhanced capacity to provide infrastructure and a high level of education for labour market entrants, to organize economic activities that move beyond the provision of generic manufactured commodities and up the industrial ladder towards services and, ultimately, the entry into the information or knowledge-based economy. The most obvious example of this is the Republic of Korea, which was at the ceasefire that ended the Civil War in 1953 one of the very poorest countries in the world but has now become not just a member of the Organization of Economic Cooperation and Development, membership of which is reserved for the richest and most influential of nations, but is one of the most wired societies of all. Its progression beyond the Middle Income Trap was accompanied by the relaxations on restrictions on democracy, within the limits noted above, construction of advanced infrastructure by the state and state support for industrial activities likely to have powerful positive externalities in development of the industry as a whole (Walsh and Techavimol, 2009). It is perhaps understandable that other states have hesitated to take this step, since powerful elites have grown fearful of losing power, money and status and, as in Thailand, have sanctioned violence to prevent meaningful political change. There are some indications that the first steps in this change are being taken in China, as the ongoing global economic crisis has begun to force a change from exporting manufactured goods to promoting domestic consumption of at least some of those products. In the case of China, it is most likely that a pragmatic and unique course of economic development and industrial policy will eventuate (Zhengyi, 2009).

Managerial Challenges: Managerial challenges are evident in both the private and public sectors and at a variety of different levels. Beginning with the public sector, it is evident that economic activities will take place more for the purpose of profit generation and less for meeting national development priorities. It may be possible to recoup some financial losses by adjusting the tax regime and to provide certain incentives to continue to move companies towards conducting the types of activities required but the nature of the relationship between state and corporation will certainly have changed. As cross-border, transportation links change the nature of distribution patterns and possibilities in the region, including virtual distribution, state agencies will need to develop better relationships with their cross-border counterparts and with transnational organizations such as the Asian Development Bank, who lead the funding component of such projects. This is likely to require more than just lip service and good manners because such organizations tend to be closely allied to agencies that require genuine action, such as the ILO and large international non-governmental organizations. More generally, appropriate and detailed 
plans will be necessary that outline the projected path for the economy and the kinds of skills and competencies needed in the jobs expected to be created. It is unlikely to be possible to match supply and demand in the future jobs market and predicting wages in such a case is notoriously difficult. However, it is possible to make some plans for providing the kinds of incentives that might be effective in persuading young people to acquire the desired skills wanted in industry. This planning will also need to consider the role of entrepreneurs in subsequent economic development and their involvement with cluster development and the industrial geography of the future. As some activities become mobile, even hyperactive mobile, the relationship between the hub of an organization and its peripheral places of assemblage and production will also need to be renegotiated. Certain core functions of the organization will remain place-bound and, for behavioral reasons, the mobility of important, skilled personnel will remain limited, finite, and capable of movement only in a certain number of directions. In other words, no amount of compensation will induce highly qualified individuals to live in undesirable locations when alternatives are open to them. Jurisdiction of operations, not to mention taxation and regulatory frameworks in force, are complicated by the nature of cross-border operations and the issues of transfer pricing, tax minimization and evasion of workplace safety standards, among others, will again become urgent issues.

In terms of the private sector, it is clear that more scope is being provided for selecting the nature of economic activities and the spatial location in which they take place. Development in transportation infrastructure has not only led to a wider range of locations and alternative options for market development. Firms in provincial areas are becoming involved in cross-border grids linking places of production and consumption, which may also be cities but need not be (Sassen, 1999). This broadens the range of locations, which are attractive from the viewpoint of investment, and the balancing act necessary to bring together those skills and competencies and resources required into appropriate spatial proximity is assisted to some extent by this broadening. Virtual networks further extend the range of operations that are possible. Hence, Singapore-based managers and professionals can work in much of Malaysia and Indonesia without having to leave their homes, while labour will no doubt be provided in the lower cost islands away from the city-state. Individuals, at least some individuals, will have more scope to choose their place of residence and work and to construct employment portfolios in a range of different occupations and means of deploying their abilities.

\section{Conclusion}

Moving from authoritarianism to post-authoritarianism entails the release of one form of power by elites and, presumably, a countervailing grabbing of power and influence in another sphere. Generally, this has involved the replacement of military power with beyond the ballot box influence and control of important economic assets in one way or another. To some extent, it is necessary to convince these elites (when they cannot be removed) to trust that desirable economic activities can take place beyond their immediate scrutiny and can be permitted to take place on the discretion of individuals and of uncontrolled corporations. This has not taken place in every country in East Asia to date and it is unlikely that it ever will, in some cases. However, that is the challenge that remains. The appropriate managerial response required to meet changes will depend to some extent on underlying ideology, the degree of democratic accountability in force and the configuration of markets and workers in the state concerned. Management styles can vary within these confines and according to the specific issue being addressed. For example, post-authoritarian uneven development is likely to feature considerable movement of people, mainly but not exclusively migrant workers. How is such movement to be managed? What implications are there for infrastructure and its development? How are there changes to be funded? Seeking to provide answers to these questions will provide a significant space in which management strategies can be implemented, monitored and refined. 


\section{References}

Amsden, A. (1992). Asia's next giant: South Korea and late industrialization. Oxford: Oxford University Press.

Balakrishnan, G. (2009). On the Stationary State. New Left Review, 59, 5-26.

Barbieri, E., Di-Tommaso, M. R. \& Bonnini, S. (2011). Industrial development policies and performances in Southern China: Beyond the specialised industrial cluster program. China Economic Review, in press.

Berger, M. T. (2003). Battering down the Chinese walls: The antinomies of Anglo-American liberalism and the history of East Asian capitalism in the shadow of the cold war, in C.J.W-L Wee (Ed.), Local cultures and the new Asia. Singapore: ISEAS. 77-106.

Cai, F. \& Wang, M. (2010). Growth and structural changes in employment in transition China, Journal of Comparative Economics, 38(1), 71-81.

Chang, J. (2011). The early and rapid internationalization of Asian emerging MNEs. Competitiveness Review: An International Business Journal incorporating Journal of Global Competitiveness, 21(2), $71-187$.

Crispin, S. W. (2007). Cambodia's cowboy capitalism. Asia Times Online (July 13). Retrieved from http://www.atimes.com/atimes/Southeast_Asia/IG13Ae01.html.

Emmerson, D. K. (1995). Singapore and the Asian values debate. Journal of Democracy, 6(4), 95-105.

Farole, T. (2011). Special economic zones in Africa. New York: The World Bank. doi:10.1596/978-0-82138638-5.

Flyvbjerg, B. (2006). Five misunderstandings about case-study research. Qualitative Inquiry, 12(2), 21945.

Ge, W. (1999). Special economic zones and the opening of the Chinese economy: Some lessons for economic liberalization. World Development, 27(7), 1267-85.

Gong, W. (1989). The legacy of Confucian culture in Maoist China. The Social Science Journal, 26(4), 36374.

Kim, B. (2010). Cultural forces and historical events to shape organizing principles in Korea: An exploratory perspective. Management Decision, 48(5), 826 - 841.

Kunmakara, M. (2010). Cheap labour pays dividends. The Phnom Penh Post (July 9). Retrieved from http://www.phnompenhpost.com/index.php/2010070940377/Business/cheap-labour-paysdividends.html.

Linn, T. (2010). Dawei deep-sea port, SEZ gets green light. Myanmar Times (November 15-21 ${ }^{\text {st }}$ ). Retrieved from http://www.mmtimes.com/2010/business/549/biz54901.html.

Marshall, A. (1890). Principles of economics. London: MacMillan.

Morris, J. (1988). The who, why and where of Japanese manufacturing investment in the UK. Industrial Relations Journal, 19(1), 31-40.

Olson, E. G. (2009). Business as environmental steward: The growth of greening. Journal of Business Strategy, 30(5), $4-13$.

Pereira, A. (2004). The Suzhou industrial park experiment: The case of China-Singapore governmental collaboration. Journal of Contemporary China, 13(38), 173-93.

Porter, M. E. (1998). Clusters and the new economics of competition. Harvard Business Review, 2, 77-90.

Preecharushh, D. (2009). Naypyidaw: New capital of Burma. Bangkok: White Lotus.

Sassen, S. (1999). Whose city is it? Globalisation and the formation of New Claims, in Foo, A.F. and Yuen, B. (eds.). Sustainable cities in the $21^{\text {st }}$ Century. Singapore: Singapore University Press, 145-62.

Wallerstein, I. (2010). Structural crises. New Left Review, 62, 133-42.

Walker, R. A. (1999). Putting capital in its place: Globalization and its prospects for labour. Geoforum, 30(3), 263-84.

Walsh, J. \& Anantarangsi, S. (2009). Management style of Chinese business owners in the Chiang Rai province of Thailand. Southeast Asian Journal of Management, 3(1), 29-40.

Walsh, J. \& Techavimol, P. (2009). Following the Korean model: Management of the online computer games industry in Thailand. GITAM Journal of Management, 7(3), 1-13.

Ward, S., Pearson, C. \& Entrekin, L. (2002). Chinese cultural values and the Asian meltdown. International Journal of Social Economics, 29(3), 205-217.

Zeng, D. Z. (2010). Building engines for growth and competitiveness in China. New York: World Bank.

Zhengyi, W. (2009). Transition paradigm, industrial policy and economic growth in China: Domestic and international forces. In Chirathivat, S. and Yuen, N.C, (eds.), Emerging Asia's growth practices: Recent experiences of China, Indonesia, Malaysia, the Philippines and Thailand. Bangkok: Chula Global Network, 35-61. 